University of Nebraska - Lincoln

DigitalCommons@University of Nebraska - Lincoln

Peter Dowben Publications

Research Papers in Physics and Astronomy

2009

\title{
Induced spin polarization of copper spin 1/2 molecular layers
}

\author{
David Wisbey \\ University of Nebraska-Lincoln \\ Ning Wu \\ University of Nebraska-Lincoln \\ Danqin Feng \\ University of Nebraska-Lincoln
}

A. N. Caruso

University of Missouri - Kansas City, carusoan@umkc.edu

J. Belot

University of Nebraska-Lincoln

See next page for additional authors

Follow this and additional works at: https://digitalcommons.unl.edu/physicsdowben

Part of the Physics Commons

Wisbey, David; Wu, Ning; Feng, Danqin; Caruso, A. N.; Belot, J.; Losovyj, Yaroslav B.; Vescovo, Elio; and Dowben, Peter A., "Induced spin polarization of copper spin 1/2 molecular layers" (2009). Peter Dowben Publications. 234.

https://digitalcommons.unl.edu/physicsdowben/234

This Article is brought to you for free and open access by the Research Papers in Physics and Astronomy at DigitalCommons@University of Nebraska - Lincoln. It has been accepted for inclusion in Peter Dowben Publications by an authorized administrator of DigitalCommons@University of Nebraska - Lincoln. 


\section{Authors}

David Wisbey, Ning Wu, Danqin Feng, A. N. Caruso, J. Belot, Yaroslav B. Losovyj, Elio Vescovo, and Peter A. Dowben 


\title{
Induced spin polarization of copper spin 1/2 molecular layers
}

\author{
David S. Wisbey ${ }^{\mathrm{a}}$, Ning $\mathrm{Wu}^{\mathrm{a}}{ }^{\text {, Danqin Feng }}{ }^{\mathrm{a}}$, A.N. Caruso ${ }^{\mathrm{b}}$, J. Belot ${ }^{\mathrm{c}}$, Ya.B. Losovyj ${ }^{\mathrm{d}}$, E. Vescovo ${ }^{\mathrm{e}}$, P.A. Dowben ${ }^{\mathrm{a}, *}$ \\ a Department of Physics and Astronomy and the Nebraska Center for Materials and Nanoscience, University of Nebraska-Lincoln, Lincoln, NE 68588-0111, USA \\ ${ }^{\mathrm{b}}$ Department of Physics, 257 Flarsheim Hall, University of Missouri - Kansas City, 5110 Rockhill Road, Kansas City, MO 64110, USA \\ ${ }^{c}$ Department of Chemistry and the Nebraska Center for Materials and Nanoscience, University of Nebraska, Lincoln, NE 68588-0304, USA \\ d Center for Advanced Microstructures \& Devices, 6980 Jefferson Hwy., Baton Rouge, LA 70806, USA \\ e Brookhaven National Laboratory, National Synchrotron Light Source, Upton, NY 11973, USA
}

\section{A R T I C L E I N F O}

\section{Article history:}

Received 6 October 2008

Received in revised form 22 November 2008

Accepted 25 November 2008

Available online 3 December 2008

Communicated by R. Wu

\section{PACS:}

75.70.Ak

75.50.Xx

75.20.-g

79.60.-i

Keywords:

Molecular magnets

Electronics states at interfaces

Spin polarized photoemission

Photoemission of organic compounds

\begin{abstract}
A B S T R A C T
Thin films of the metal organic molecule bis(4-cyano-2,2,6,6-tetramethyl-3,5-heptanedionato)copper(II) (or $\left.\mathrm{Cu}(\mathrm{CNdpm})_{2}\right),\left(\mathrm{C}_{24} \mathrm{H}_{36} \mathrm{~N}_{2} \mathrm{O}_{4} \mathrm{Cu}, \mathrm{Cu}(\mathrm{II})\right)$, deposited on ferromagnetic $\mathrm{Co}(111)$ at $40 \mathrm{~K}$, exhibit a finite electron spin polarization. The spin polarization magnitude and sign for $\mathrm{Cu}(\mathrm{CNdpm})_{2}$ deposited on $\mathrm{Co}(111)$ is coverage dependent, but deviates from the mean field expectations for a simple paramagnet on a ferromagnetic substrate. The spin asymmetry is seen to favor select molecular orbitals, consistent with the predicted single molecule density of states. The overlayer polarization observed indicates a strong influence of the ferromagnetic $\mathrm{Co}(111)$ substrate and some extra-molecular magnetic coupling.
\end{abstract}

(C) 2008 Elsevier B.V. All rights reserved.

\section{Introduction}

Ferromagnetic substrates can induce magnetic moments in large molecular adsorbates [1-3], as well as small adsorbate species. The induced magnetic ordering in a paramagnetic adsorbate, due to a ferromagnetic substrate, can be roughly described by the Ginzburg-Landau equation [4-6]. This is a mean field "proximity effect", characterized by an exponential decay of the magnetization with film thickness $z$ as:

$M(z)=R \bullet \exp (-\kappa z)$

with a temperature dependent characteristic paramagnetic correlation length $\kappa^{-1}$ [4-6], related to short range magnetic order. This mean field approximation (Ginzburg-Landau) does not, however, explain the origin of the adsorbate paramagnetic correlation length or the mechanisms (microscopic Hamiltonian) for induced magnetic ordering in molecular adlayers [6]. While there is an increas-

\footnotetext{
* Corresponding author.

E-mail address: pdowben@unl.edu (P.A. Dowben).
}

ing body of data that does tend to support ferromagnetic substrate induced magnetic moments for large molecular adsorbates [1-3], the role of magnetic coupling, and the role of the different interfaces remain very open questions.

Unraveling the nature of magnetic coupling in organic layers with induced magnetization, here the organic bis(4-cyano2,2,6,6-tetramethyl-3,5-heptanedionato)copper(II) (or $\mathrm{Cu}(\mathrm{CNdpm})_{2}$ ), $\left(\mathrm{C}_{24} \mathrm{H}_{36} \mathrm{~N}_{2} \mathrm{O}_{4} \mathrm{Cu}, \mathrm{Cu}(\mathrm{II})\right)$, is the focus of this Letter. In principle, $\mathrm{Cu}(\mathrm{CNdpm})_{2}$ is a spin $1 / 2$ system without complications from spin-orbit coupling [7]. The molecule $\mathrm{Cu}(\mathrm{CNdpm})_{2}$ was shown to have a magnetic moment of $1.05 \pm 0.04 \mu_{\mathrm{B}}$ per molecule and a positive Weiss constant $(23 \mathrm{~K})$ was measured indicating weak ferromagnetic exchange between molecules [7]. This occurs in spite of the fact that $\mathrm{Cu}(\mathrm{CNdpm})_{2}$ molecular films are not metallic, with a relatively large highest occupied to lowest unoccupied molecular orbital gap [7].

Our goal here is to examine, in detail, the spin polarization of the metal organic molecule $\mathrm{Cu}(\mathrm{CNdpm})_{2}$ deposited on $\mathrm{Co}(111)$. Like the metal phthalocyanines adsorbed on ferromagnetic substrates $[1,2]$, thin molecular thin films of $\mathrm{Cu}(\mathrm{CNdpm})_{2}$ on a ferromagnetic $\mathrm{Co}(111)$ substrate will also exhibit spin polarization. 


\section{Methods}

The synthesis of bis(4-cyano-2,2,6,6-tetramethyl-3,5-heptanedionato)copper(II) (or $\left.\mathrm{Cu}(\mathrm{CNdpm})_{2}\right),\left(\mathrm{C}_{24} \mathrm{H}_{36} \mathrm{~N}_{2} \mathrm{O}_{4} \mathrm{Cu}, \mathrm{Cu}\right.$ (II)) was described previously $\left.[7,8] . \mathrm{Cu}(\mathrm{CNdpm})_{2}\right)$ was isolated as large, blue block crystals ( $>1 \mathrm{~cm}$ on an edge) that exhibit high thermal stability $(>400 \mathrm{~K})$, reasonable volatilities. For bulk crystals of $\mathrm{Cu}(\mathrm{CNdpm})_{2}$, the immediate coordination geometry about $\mathrm{Cu}(\mathrm{II})$ is a tetragonally distorted octahedron exhibiting four short $\mathrm{Cu}-\mathrm{O}$ equatorial bonds and two trans axial $\mathrm{Cu}-\mathrm{N}$ bonds $[7,8]$. But this tetragonal structure is not likely adopted with adsorption on $\mathrm{Co}(111)$ [3]. $\mathrm{Cu}(\mathrm{CNdpm})_{2}$ does adopt a preferential orientation when deposited on the surface of $\mathrm{Cu}(111)$ or $\mathrm{Co}(111)$ that changes as the thickness increases [3].

Molecular thin films of $\mathrm{Cu}(\mathrm{CNdpm})_{2}$ were adsorbed on epitaxial $\mathrm{Co}(111)$ thin films, freshly grown on $\mathrm{Cu}(111)$. The molecule $\mathrm{Cu}(\mathrm{CNdpm})_{2}$ was deposited from the vapor as described in prior work [3,7]. The $\mathrm{Cu}(\mathrm{CNdpm})_{2}$ molecules were deposited on $\mathrm{Co}(111)$ substrates at about $40 \mathrm{~K}$. Adequate $\mathrm{Cu}(\mathrm{CNdpm})_{2}$ vapor pressure was obtained by subliming the molecule at a temperature of approximately $350 \mathrm{~K}\left(80^{\circ} \mathrm{C}\right)$. Clean $\mathrm{Cu}(111)$ substrate surfaces were prepared by repeated cycles of $\mathrm{Ar}^{+}$ion sputtering and annealing of a $\mathrm{Cu}$ single crystal. The epitaxial $\mathrm{Co}(111)$ thin film substrates were grown in situ on a clean $\mathrm{Cu}(111)$ single crystal to a thickness of $20 \AA$ and characterized by low-energy electron diffraction (LEED), photoemission, and spin-polarized photoemission. Typically, epitaxial $\mathrm{Co}(111)$ layers on $\mathrm{Cu}(111)$ possessed $20-40 \%$ spin polarization, depending on the incident photon energy and film thickness, consistent with the literature [9-13]. Care was taken to avoid photodecomposition of the molecular film during photoemission experiments, as studied in detail and described elsewhere [14].

Spin polarized angle resolved photoemission spectra were acquired at the U5UA undulator spherical grating monochromator (SGM) beamline at the National Synchrotron Light Source (NSLS) [15-17]. Linearly polarized light from an undulator source was monochromatized using a spherical grating monochromator (SGM) operating in the range 20 to $150 \mathrm{eV}$. The ultra-high-vacuum photoemission end station was equipped with a commercial angleresolved hemispherical electron energy analyzer (EA125, Omicron $\mathrm{GmbH}$ ) and a post electron energy analyzer Mott detector for spin polarization analysis [15-17]. The spin polarization $P$ for the collected data was determined according to

$P=\frac{1}{2} \frac{\sqrt{I_{L}^{+} I_{R}^{-}}-\sqrt{I_{L}^{+} I_{R}^{-}}}{\sqrt{I_{L}^{+} I_{R}^{-}}+\sqrt{I_{L}^{+} I_{R}^{-}}}$

where $I_{L}$ and $I_{R}$ represent the number of electrons scattered into the left and right channels of the Mott detector, respectively. Spin minority and spin majority spectra are thus taken simultaneously. To eliminate instrumental asymmetry, it was necessary to measure the sample magnetized "up" $\left(I_{L}^{+}, I_{R}^{+}\right)$and the sample magnetized "down" $\left(I_{L}^{-}, I_{R}^{-}\right)$, although the spectra themselves were taken at remanence. Spin polarization was calculated using a Sherman function of $S=0.15$. The analyzer has a $\pm 2^{\circ}$ angular resolution, while the combined energy resolution of the analyzer and the light source was approximately $150 \mathrm{meV}$ or less. The photoemission spectra were taken at $45^{\circ}$ light incidence angle, with the photoelectrons collected normal to the surface, unless indicated otherwise. Throughout this Letter, all binding energies are referenced to the substrate Fermi level, and angles are defined with respect to the substrate surface normal. In general, the spectra were taken at photon energies in the region of $49-50 \mathrm{eV}$, so secondary background subtraction from the spectra was not necessary and the spectra shown are as taken.

\section{Spin asymmetry}

Spin polarized photoemission spectroscopy of adsorbed $\mathrm{Cu}-$ $(\mathrm{CNdpm})_{2}$ molecular thin films deposited on epitaxial $\mathrm{Co}(111)$ at $40 \mathrm{~K}$ are shown in Fig. 1 (blue and red lines represent spin majority and minority states, respectively). We found spin asymmetries $40 \%$ near the Fermi edge in the $3 \mathrm{~d}$ band of the clean $\mathrm{Co}(111)$ substrate, as reported for Co [9-13]. The cobalt 3d bands exhibit an exchange splitting near the Fermi edge (Fig. 1(a)) of about $1 \mathrm{eV}$ consistent with the literature [12-16]. $\mathrm{Cu}(\mathrm{CNdpm})_{2}$ deposited on clean $\mathrm{Co}(111)$ at $40 \mathrm{~K}$ leads to a decrease in the observed spin majority polarization near the Fermi edge, in spin polarized photoemission spectroscopy, at one molecular monolayer (ML) coverage (Fig. 1(b)), followed by an increase in the spin minority polarization with increasing molecular film coverages (Fig. 1(c)).

At ten molecular monolayers, there is no spectral density from the $\mathrm{Co}(111)$ substrate in our photoemission spectra (Fig. 1(c)), as noted in more detail elsewhere [3]. Thus the observed spin polarization is the result of induced polarization in the $\mathrm{Cu}(\mathrm{CNdpm})_{2}$ molecular adlayer. Substrate contributions to the observed spin asymmetry observed in the photoemission from monomolecular films cannot be excluded by any means, and indeed are a likely contribution to the thinner molecular films due to the finite electron mean free path. The increase in the spin minority population, with molecular adsorption occurs at somewhat higher binding energies corresponding to the higher occupied molecular orbitals of $\mathrm{Cu}(\mathrm{CNdpm})_{2}$, as seen in Fig. 1, and is assigned to the photoemission features resulting from the $\mathrm{Cu}(\mathrm{CNdpm})_{2}$ molecular orbitals.

Calculations for a single $\mathrm{Cu}(\mathrm{CNdpm})_{2}$ molecule predict an inherent spin polarization for specific molecular orbitals, as indicated in Fig. 1(d). These model calculations of the density of states are based on a simplistic semi-empirical method for determin-

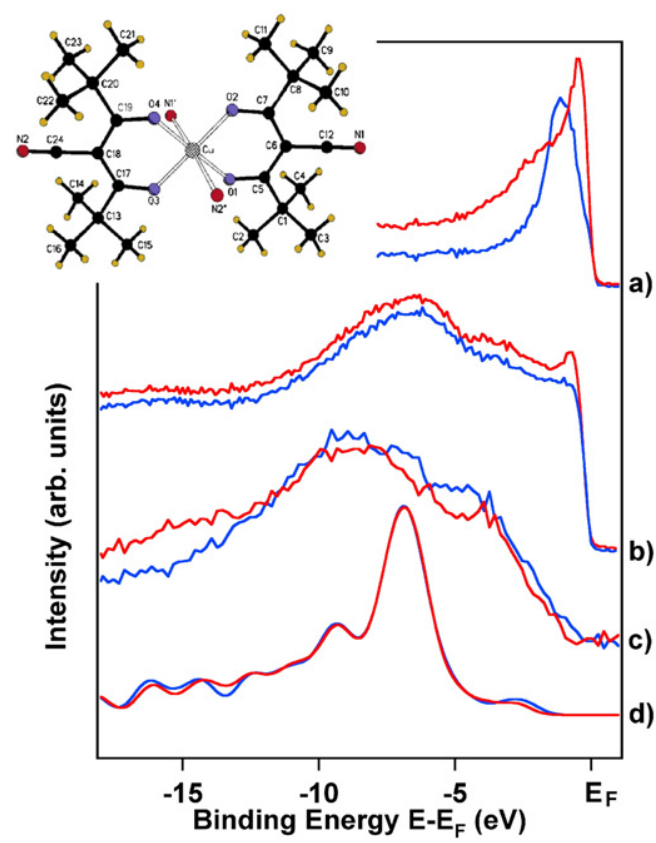

Fig. 1. The spin polarization photoemission spectra of epitaxial $\operatorname{Co}(111)$ and $\mathrm{Cu}(\mathrm{CNdpm})_{2}$ molecular layers on $\mathrm{Co}(111)$ at $40 \mathrm{~K}$ : spin majority is indicated by red, spin minority by blue. The spin polarized photoemission spectrum of $20 \AA$ of epitaxial $\mathrm{Co}(111)$ on $\mathrm{Cu}(111)$, taken at $\sim 40 \mathrm{~K}$ and a photon energy of $49 \mathrm{eV}$, is shown (a) to indicate the substrate polarization. One monolayer of molecular $\mathrm{Cu}(\mathrm{CNdpm})_{2}$ on $\mathrm{Co}(111)$ (b), and 10 monolayers of molecular $\mathrm{Cu}(\mathrm{CNdpm})_{2}$ on $\mathrm{Co}(111)$ (c) both show differences in the spin polarized photoemission. The photon energy used in spectra (a) and (c) was $49 \mathrm{eV}$, and the photon energy used in spectrum (b) was $41.5 \mathrm{eV}$. Photons where incident on the sample at $45^{\circ}$ with the photoelectrons collected at normal emission. For comparison, the single molecule model density of states calculations is shown in (d). The inset is a schematic of the $\mathrm{Cu}(\mathrm{CNdpm})_{2}$ molecule. 
ing the ground state molecular orbitals (NDO-PM3 or neglect of the differential diatomic overlap, parametric model number 3 [18]) for a single $\mathrm{Cu}(\mathrm{CNdpm})_{2}$ molecule. Although PM3 is a simplistic semiempirical calculation, density functional theory (DFT) is notorious for under estimating the band gap, sometimes by a factor 2 or more [19], particularly for molecular systems, and must be rescaled for comparison with experiment [20], particularly final state spectroscopies like photoemission and inverse photoemission. To compare the model calculations with experiment (Fig. 1), we applied Gaussian envelopes of $1.2 \mathrm{eV}$ full width half maximum to each calculated molecular orbital energy (eigen value) to account for the solid state broadening in photoemission and then summed. These model density of states calculations are rigidly shifted in energy by $4.4 \mathrm{eV}$ and then compared with the combined photoemission data, as indicated in Fig. 1 . The $4.4 \mathrm{eV}$ energy shift which is, for the most part, representative of the work function $\Phi$ equal to the difference of vacuum energy $E_{\mathrm{vac}}$ and Fermi level $E_{F}$, is applied to the calculated electronic structure uniformly. No corrections were made for final state effects or matrix element effects in the model calculations, so the comparison with experiment is very simplistic, but nonetheless still often successful [7,21-23].

It is clear that the spin asymmetry depends on the molecular orbital contributions in both the experimental data (Figs. 1(b) and 1(c)) and the model calculations (Fig. 1(d)), as has been noted elsewhere [3]. The highest occupied molecular orbital (HOMO), at about 3 to $4 \mathrm{eV}$ binding energy, has the largest spin asymmetry.

\section{Induced magnetic ordering}

If the observed spin polarization for molecular thin films of $\mathrm{Cu}(\mathrm{CNdpm})_{2}$ deposited on $\mathrm{Co}(111)$ in Fig. 1 is merely the result of the ferromagnetic substrate polarizing the molecule then the spin polarization should decay exponentially with thickness, in the context of the Ginzburg-Landau model (Eq. (1)). This mean field approximation can be applied to a paramagnetic substance deposited on a ferromagnetic substrate for thin layers, but does not provide insight into the microscopic mechanisms for coupling. Indeed, if applicable at all, the mean field approximation should apply to similar metal centered macrocyclic molecules like $\mathrm{Cu}$ phthalocyanine (CuPc).

Copper phthalocyanine (CuPc) is a similar disk shaped metalorganic molecule that displays interesting magnetic properties $[1,2]$. Suzuki et al. also found spin polarization in thin films of CuPc on $\mathrm{Fe}(100)$ [1,2]. Figs. 2(a) and 2(b) show the spin asymmetry of 1 monolayer (ML) of CuPc deposited on $\mathrm{Fe}(100)$ and 10 monolayers (ML) of $\mathrm{Cu}(\mathrm{CNdpm})_{2}$ deposited on $\mathrm{Co}(111)$, respectively. The highest measured spin asymmetry reported for CuPc on $\mathrm{Fe}(100)$ is around $5-6 \%$ [1]. As the CuPc thickness increases, the spin polarization decays exponentially as shown in Fig. 3(b). These data were taken using metastable helium atom quenching, and hence are much more surface sensitive than the spin polarized photoemission data taken for $\mathrm{Cu}(\mathrm{CNdpm})_{2}$, but some limited comparison is possible.

While the analysis of our data for $\mathrm{Cu}(\mathrm{CNdpm})_{2}$ deposited on $\mathrm{Co}(111)$, herein, and published data for $\mathrm{Cu}$ phthalocyanine (CuPc) deposited on $\mathrm{Fe}(100)$ [1] shows that there is indeed an exponential change in the polarization (Fig. 3), this is NOT a simple exponential, as in Eq. (1). The decay does not appear to tend towards zero for either metal organic species. We found that the exponential component, neglecting the additional constant factor in the fit to the data, indicates a paramagnetic correlation length for $\mathrm{CuPc}$ on $\mathrm{Fe}(100)$ to be $\kappa^{-1} \sim 0.77 \pm 0.11$ monolayers (ML). For the thin films of $\mathrm{Cu}(\mathrm{CNdpm})_{2}$ on $\mathrm{Co}(111)$ we found the correlation length to be $\kappa^{-1} \sim 1.7 \pm 0.7$ monolayers (ML), with the addition of a constant term. The correlation lengths were found in both cases by fitting the data for $\mathrm{CuPc}$ on $\mathrm{Fe}(100)$ (from [1]) and $\mathrm{Cu}(\mathrm{CNdpm})_{2}$ on

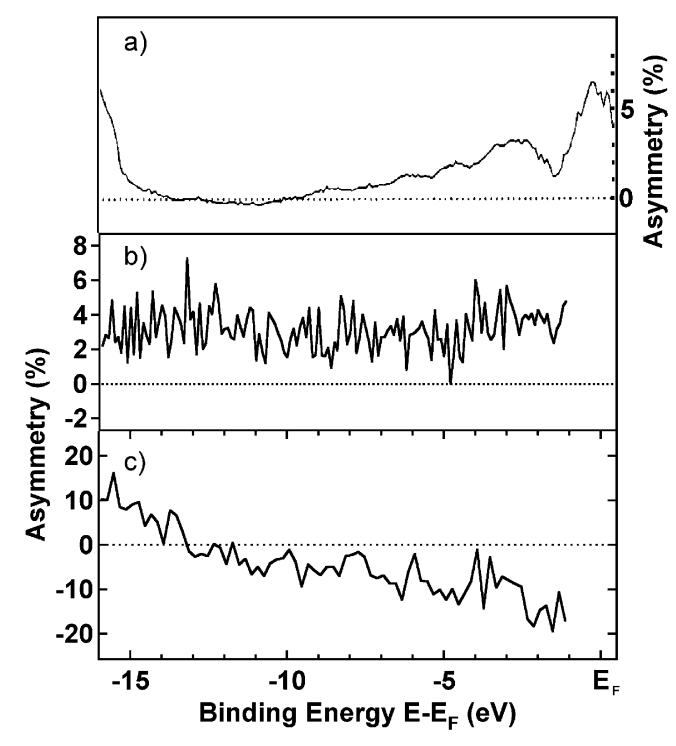

Fig. 2. The spin asymmetry of 1 monolayer of CuPc deposited on Fe(100) (a) obtained with spin-polarized mestable helium atom de-excitation spectroscopy [1], compared to the spin asymmetry of 1 monolayer (b) and 10 monolayers (c) of $\mathrm{Cu}(\mathrm{CNdpm})_{2}$ deposited on $\mathrm{Co}(111)$ at $40 \mathrm{~K}$. The spin polarized photoemission data for $\mathrm{Cu}(\mathrm{CNdpm})_{2}$ was taken with the $\mathrm{Co}(111)$ substrate at approximately $40 \mathrm{~K}$, using a $49 \mathrm{eV}$ photon energy with photon incidence angle of $45^{\circ}$ with electrons collected at surface normal. Asymmetry data for CuPc was taken from Ref. [1], where spin polarized metastable He atom quenching spectroscopy was used.

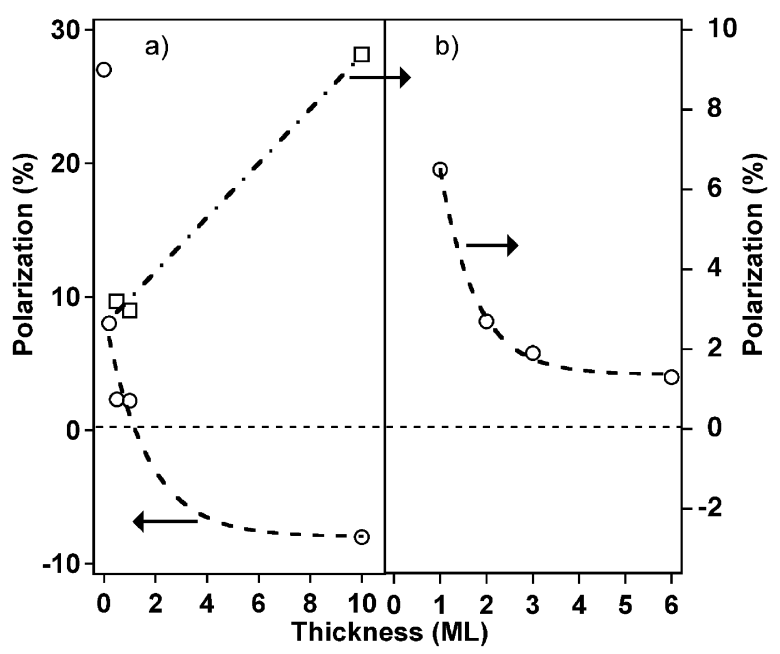

Fig. 3. (a) Spin polarization asymmetry as a function of thickness for $\mathrm{Cu}(\mathrm{CNdpm})_{2}$ on $\mathrm{Co}(111)$ at temperatures of $\sim 40 \mathrm{~K}$. The data for $\mathrm{Cu}(\mathrm{CNdpm})_{2}$ on $\mathrm{Co}(111)$ in (a) is plotted both for the polarization obtained in the region of $3 \mathrm{eV}$ binding energy (indicated by - $O$-dashed line) as well as for a binding energy of $15 \mathrm{eV}$ (indicated by $-\square$ - and the dashed-dot line). Spin polarization as a function of thickness for CuPc deposited on Fe(100), abstracted from Ref. [1], is plotted in (b). The arrows indicate the appropriate polarization scale that applies to each data set.

Co(111) shown in Fig. 3 with Eq. (1). These values for the paramagnetic correlation length are only approximate as we are not strictly surface sensitive: the photoelectrons have a finite mean free path of 5-10 A. A rather large paramagnetic correction length, similar to that for $\mathrm{Cu}(\mathrm{CNdpm})_{2}$ on $\mathrm{Co}(111)$, also might be inferred for pentacene based on the spin-polarized metastable helium atom de-excitation spectra taken for pentacene adlayers on $\mathrm{Fe}(100)$ [24].

While Eq. (1) works well for the initial coverages of CuPc on $\mathrm{Fe}(100)$ and $\mathrm{Cu}(\mathrm{CNdpm})_{2}$ deposited on $\mathrm{Co}(111)$, the persistence of spin polarization at the higher molecular coverages suggests a more complicated picture for the induced spin polarization of these molecular overlayers. The decay constant does appear to be 
correct for a molecular paramagnet, in the case of $\mathrm{CuPc}$ on $\mathrm{Fe}(100)$, with correlation lengths on the length scale of about a molecule, were the polarization to decay to zero with increasing film thickness.

As the thickness of the molecular $\mathrm{Cu}(\mathrm{CNdpm})_{2}$ coverage on $\mathrm{Co}(111)$ increases, the magnitude of the spin polarization decreases then increases while becoming negative, at a binding energy of about 3-4 eV (the position of maximum polarization asymmetry for $\mathrm{Cu}(\mathrm{CNdpm})_{2}$ on $\left.\mathrm{Co}(111)\right)$. If $\mathrm{Cu}(\mathrm{CNdpm})_{2}$ followed the Ginzburg-Landau model for a paramagnet on a ferromagnetic substrate, the spin polarization should decrease exponentially to zero, according to Eq. (1), while maintaining the same direction of spin polarization as the substrate. A deviation from Eq. (1) in the Ginzburg-Landau model and the observed spin polarization is not merely the result of the remnant magnetic field of the ferromagnetic $\mathrm{Co}(111)$ substrate magnetizing the adsorbed $\mathrm{Cu}(\mathrm{CNdpm})_{2}$ layer. The constant added to Eq. (1) allows the data to be fit quite well (as for $\mathrm{Cu}(\mathrm{CNdpm})_{2}$ on $\mathrm{Co}(111)$ in Fig. 3(a) and for CuPc on $\mathrm{Fe}(100)$ in Fig. 3(b)) for the spin polarization obtained at some binding energies (but not all, as noted below). Because the fits to the data (dashed lines) in Fig. 3(b) are exponential fits of the spin asymmetry data using Eq. (1) with an added constant, expectations from mean field theory are not met. Without the addition of a constant, the data points in Fig. 3 for higher molecular coverages are not well fit by Eq. (1).

The deviation from the expectations of Ginzburg-Landau mean field theory is also evident when one looks at the polarization at $15 \mathrm{eV}$ binding energy, as plotted in Fig. 3 for $\mathrm{Cu}(\mathrm{CNdpm})_{2}$ on $\mathrm{Co}(111)$. As seen in Fig. 3 (with a fit plotted as a dash-dot line), the polarization increases, at these greater binding energies, with increasing $\mathrm{Cu}(\mathrm{CNdpm})_{2}$ film thickness on $\mathrm{Co}(111)$, although no change in the sign of the polarization is observed.

Induced polarization in an adsorbate, by a ferromagnetic substrate is known and has been identified in a wide variety of adsorbates. Indeed, it is expected that for a ferromagnetic metal, such as $\mathrm{Ni}, \mathrm{Fe}$, and $\mathrm{Co}$, the $3 \mathrm{~d}$ orbitals overlap into an adsorbate layer. Studies of physisorbed Xe [25,26] and chemisorbed $O$ [27] and I [28] adsorbed onto Co and Fe surface confirm 3d orbitals overlap into the adsorbate. Measured spin polarization is due to interaction with the substrate.

For chemisorbed oxygen $(0)$ on the surface of iron $(\mathrm{Fe})$, the $02 \mathrm{p}_{x}$ and $2 \mathrm{p}_{y}$ bands have been shown to hybridize with $\mathrm{Fe} 3 \mathrm{~d}_{x y}$ band and the $02 \mathrm{p}_{z}$ band hybridizes with the $\mathrm{Fe} 3 \mathrm{~d}_{3 z^{2}-r^{2}}$ band $[28,29]$. Hybridization of the iodine (I) $5 \mathrm{p}_{x y}$ and $5 \mathrm{p}_{z}$ orbitals may also be responsible for the observed spin polarization of chemisorbed I on the surface of $\mathrm{Fe}(110)$ [28]. Similarly, spin polarized photoemission studies reveal that spin polarization is observable in physisorbed $\mathrm{Xe}$ on $\mathrm{Fe}(110), \mathrm{Fe}(100)$, and $\mathrm{Co}(0001)$ crystal thin films $[25,26]$. Xenon should have no magnetic moment due to its completely filled electronic shell. When Xe is ionized it has the same electronic configuration as I and goes from being physisorbed to forming a chemical bond with the Co substrate. Photoionization can remove only one electron from Xe and results in a spin polarized photoemission spectra $[25,26]$. However, in the case of physisorbed $\mathrm{Xe}$, the spin splitting is a final state effect rather than an initial state effect as in the case of chemisorbed species $[25,26]$. Therefore, some interaction must occur between the Co substrate, specifically the Co $3 \mathrm{~d}$ orbitals, and the Xe $5 \mathrm{p}$ orbitals. Studies of Xe on Fe(100) by Getzlaff and colleagues $[25,26]$ revealed that the distance between the sample and the adsorbate was quite important. After about $4 \AA$, the ferromagnetic $3 \mathrm{~d}$ orbitals do not significantly overlap into the adsorbed Xe [25]. They found that for distances of $2 \AA$ the overlap is much stronger than for greater distances and is responsible for the initial state spin polarization occurring in chemisorbed atoms such as I and $O[25,26]$. For pentacene on $\mathrm{Fe}(100)$ [24], it may well be that the paramag-

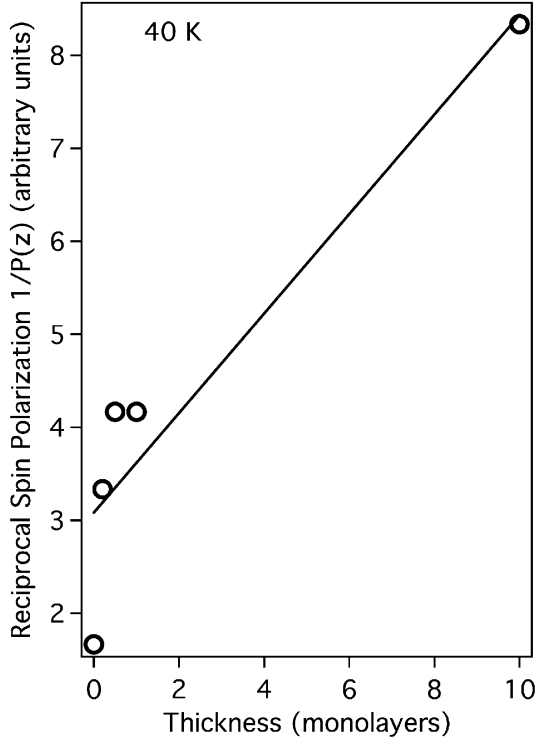

Fig. 4. Reciprocal spin polarization for $\mathrm{Cu}(\mathrm{CNdpm})_{2}$ on $\mathrm{Co}(111)$ at temperatures of $\sim 40 \mathrm{~K}$, in the region of $3-4 \mathrm{eV}$ binding energy. Data shown in this figure is the reciprocal of the spin polarization data (indicated by - $\bigcirc$-dashed line) shown in Fig. 3. The straight line is a linear fit of the reciprocal spin polarization data.

netic correlation length of pentacene is simply very large, and that otherwise the induced spin polarization follows the expectations of Ginzburg-Landau theory.

What is unusual here with these large metal organic species, particularly for $\mathrm{Cu}(\mathrm{CNdpm})_{2}$, is that the spin polarization of $\mathrm{Cu}(\mathrm{CNdpm})_{2}$ is larger than the expected value from Eq. (1) for 10 monolayers (ML) on $\mathrm{Co}(111)$. Where the coverage dependence in mean field theory results in a $\left|M^{\prime}(y)\right|_{y=z}$ that is positive and large (represented by a nonzero polarization either positive or negative) for a significant film thickness $y$, there is a live surface layer [5]. Thus, our results here suggest that the surface layer of $\mathrm{Cu}(\mathrm{CNdpm})_{2}$ molecules on $\mathrm{Co}(111)$ has a magnetic ordering behavior different from the bulk of the molecular thin film. Whatever the origin for the thickness dependence of the spin polarization of $\mathrm{Cu}(\mathrm{CNdpm})_{2}$ molecular films on $\mathrm{Co}(111)$, extra-molecular coupling must be invoked, and this is certainly consistent with the weak intermolecular coupling found in magnetometry [7]. The same may well be true of $\mathrm{CuPc}$ on $\mathrm{Fe}(100)$, but the case is less compelling.

While it is possible that $\mathrm{Cu}(\mathrm{CNdpm})_{2}$ on $\mathrm{Co}(111)$ at $40 \mathrm{~K}$ is ferromagnetic, unfortunately, we cannot, as yet make a compelling case that this is indeed the case from the available data. There is not enough data to establish the expected linear relationship of $\left|M^{\prime}(z)^{-1}\right|[30,31]$ expected for a weak ferromagnet $\left(\mathrm{Cu}(\mathrm{CNdpm})_{2}\right)$ on a stronger ferromagnet (cobalt), as seen in Fig. 4. We have also not identified spin polarization for adsorbed $\mathrm{Cu}(\mathrm{CNdpm})_{2}$ on a nonmagnetic substrate as yet [3]. There is also the complication that the preferential molecular orientation is dependent on the interface and film thickness [3]. Changing the interface alters the preferential orientation of the molecules, so we cannot exclude that the packing of $\mathrm{Cu}(\mathrm{CNdpm})_{2}$ on substrates other than $\mathrm{Co}(111)$ is not a molecular packing favorable to an intermolecular magnetic coupling that is strong enough to sustain molecular magnetism. Thus much more investigation, along the line presented here, for a variety of local moment molecular systems, is clearly indicated.

\section{Summary}

Spin polarization was observed in molecular thin films of $\mathrm{Cu}(\mathrm{CNdpm})_{2}$ grown on epitaxial $\mathrm{Co}(111)$ indicating magnetic order. The overall direction of spin polarization of these molecular thin 
films for 1 monolayer (ML) was the same as the substrate, but reversed spin polarization for 10 monolayers (ML). Spin polarization of $\mathrm{Cu}(\mathrm{CNdpm})_{2}$ molecular thin films did not universally decay exponentially as thickness increased, indicating a deviation from the Ginzburg-Landau model for a simple paramagnet on a ferromagnet. If $\mathrm{Cu}(\mathrm{CNdpm})_{2}$ is a paramagnet on $\mathrm{Co}(111)$ at $40 \mathrm{~K}$, then it is very likely that the surface of the molecular film exhibits a sort of "live" magnetic behavior, not easily suppressed. The model spin polarized density of states calculations for a single $\mathrm{Cu}(\mathrm{CNdpm})_{2}$ molecule show spin polarization for specific molecular orbitals that are consistent with the spin polarized photoemission spectra.

\section{Acknowledgements}

This research was supported by the National Science Foundation through grant Nos. CHE-0415421 and CHE-0650453 and through the Materials Research Science and Engineering Center at University of Nebraska-Lincoln (grants MRSEC DMR-0213808 and DMR-0820521).

\section{References}

[1] T. Suzuki, M. Kurahashi, Y. Yamauchi, J. Phys. Chem. B 106 (2002) 7643.

[2] T. Suzuki, M. Kurahashi, X. Ju, Y. Yamauchi, J. Phys. Chem. B 106 (2002) 11553.

[3] D. Wisbey, N. Wu, D. Feng, A.N. Caruso, J. Belot, Y. Losovyj, E. Vescovo, P.A. Dowben, J. Phys. Chem. C 112 (2008) 13656.

[4] D. Schwenk, F. Fishman, F. Schwabl, Phys. Rev. B 38 (1988) 11618.

[5] P.A. Dowben, D. LaGraffe, D.Q. Li, A. Miller, L. Zhang, L. Dottl, M. Onellion, Phys. Rev. B 43 (1991) 3171.

[6] E.M. Lifshitz, L.P. Pitaelevski, Statistical Physics, Part 2, Pergamon, Oxford, 1980.

[7] D. Wisbey, D. Feng, M.T. Bremer, C.N. Borca, A.N. Caruso, C.M. Silvernail, J. Bellot, E. Vescovo, L. Ranno, P.A. Dowben, J. Am. Chem. Soc. 129 (2007) 6249.
[8] C.M. Silvernail, G. Yap, R.D. Sommer, A.L. Rheingold, V.W. Day, J.A. Belot, Polyhedron 20 (2001) 3113

[9] U. Alkemper, C. Carbone, E. Vescovo, W. Eberhardt, O. Rader, W. Gudat, Phys. Rev. B 50 (1994) 17496.

[10] E. Vescovo, C. Carbone, U. Alkemper, O. Rader, T. Kachel, W. Gudat, W. Eberhardt, Phys. Rev. B 52 (1995) 13497.

[11] J. Izquierdo, A. Vega, L.C. Balbás, Surf. Sci. 352-354 (1996) 902.

[12] C.M. Schneider, J.J. de Miguel, P. Bressler, P. Schuster, R. Miranda, J. Kirschner, J. Electron Spectrosc. Relat. Phenom. 51 (1990) 263.

[13] D.H. Yu, M. Donath, J. Braun, G. Rangelov, Phys. Rev. B 68 (2003) 155415.

[14] D. Wisbey, N. Wu, Y. Losovyj, I. Ketsman, A.N. Caruso, D. Feng, J. Belot, E. Vescovo, P.A. Dowben, Appl. Surf. Sci. (2008), in press.

[15] E. Vescovo, H.-J. Kim, Q.-Y. Dong, G. Nintzel, D. Carlson, S. Hulbert, N.V. Smith, Synch. Rad. News 12 (1999) 10.

[16] P.D. Johnson, N.B. Brooks, S.L. Hulbert, R. Klaffy, A. Clarke, B. Sinković, N.V Smith, R. Celotta, M.H. Kelly, D.T. Pierce, M.R. Scheinfein, B.J. Waclawski, M.R. Howells, Rev. Sci. Instrum. 63 (1992) 1902.

[17] P.D. Johnson, Rep. Prog. Phys. 60 (1997) 1217.

[18] J.J.P. Stewart, Encyclopedia of Computational Chemistry, Wiley, 1998.

[19] I.N. Yakovkin, P.A. Dowben, Surf. Rev. Lett. 14 (2007) 481.

[20] A.M. Scheer, P.D. Burrow, J. Phys. Chem. B 110 (2006) 17751

[21] J. Liu, J. Xiao, S.-B. Choi, P. Jeppson, L. Jarabek, Ya.B. Losovyj, A.N. Caruso, P.A Dowben, J. Phys. Chem. B 110 (2006) 26180.

[22] D.-Q. Feng, D. Wisbey, Y. Tai, Ya.B. Losovyj, M. Zharnikov, P.A. Dowben, J. Phys. Chem. B 110 (2006) 1095.

[23] J. Xiao, M. Poulsen, S. Reddy, J.M. Takacs, Ya.B. Losovyj, P.A. Dowben, Polym. Eng. Sci. 48 (2008) 1649.

[24] T. Suzuki, M. Kurahashi, X. Ju, Y. Yamauchi, Surf. Sci. 549 (2004) 97.

[25] M. Getzlaff, N.A. Cherepkov, G. Schönhense, Phys. Rev. B 52 (1995) 3421.

[26] M. Getzlaff, J. Bansmann, G. Schönhense, Phys. Rev. Lett. 71 (1993) 793.

[27] W. Clemens, E. Vescovo, T. Kachel, C. Carbone, W. Eberhardt, Phys. Rev. B 46 (1992) 4198.

[28] M. Getzlaff, J. Bansmann, G. Schönhense, Phys. Lett. A 182 (1993) 153.

[29] H. Huang, J. Hermanson, Phys. Rev. B 32 (1985) 6312.

[30] A. Miller, P.A. Dowben, J. Phys. Condens. Matter 5 (1993) 5459.

[31] P.A. Dowben, W. Hürsch, M. Landolt, J. Magn. Magn. Mater. 125 (1993) 120. 